\title{
EFFECT OF RUTHENIUM ON MICROSTRUCTURE AND STRESS RUPTURE PROPERTIES OF A SINGLE CRYSTAL NICKEL-BASE SUPERALLOY
}

\author{
Yafang Han ${ }^{1,2}$, Wenyou Ma ${ }^{1}$, Ziqiang Dong ${ }^{1}$, Shusuo $\mathrm{Li}^{1}$, Shengkai Gong ${ }^{1}$ \\ ${ }^{1}$ School of Materials Science and engineering, Beijing University of Aeronautics and Astronautics; Beijing 100083, China \\ ${ }^{2}$ Beijing Institute of Aeronautical Materials; Beijing 100095, China
}

Keywords: Single Crystal, Ruthenium, TCP Phase, Stress Rupture

\begin{abstract}
The effect of $\mathrm{Ru}$ on microstructure and stress rupture properties of an advanced Ni base single crystal alloy has been investigated. The experimental results showed that the addition of $4 \mathrm{wt} . \% \mathrm{Ru}$ had hardly effect on the phase precipitation behavior of as-cast alloy, i. e., the microstructure is composed of $\gamma$ and $\gamma^{\prime}$ phases for both $\mathrm{Ru}$ free and $\mathrm{Ru}$ containing alloys. However, under the heat treatments of $1305^{\circ} \mathrm{C}-1315^{\circ} \mathrm{C} / 16 \mathrm{~h}$ solutioning and $1140^{\circ} \mathrm{C} / 4 \mathrm{~h}+$ $870^{\circ} \mathrm{C} / 20 \mathrm{~h}$ aging, and the thermal exposure under $1100^{\circ} \mathrm{C} / 1000 \mathrm{~h}$, the addition of $4 \mathrm{wt} . \% \mathrm{Ru}$ restrained the precipitation and growth of TCP phase evidently, and increased the rafting structure tendency of $\gamma / \gamma^{\prime}$ phases. The results of stress rupture tests showed that the addition of $4 \mathrm{wt} \% \mathrm{Ru}$ in the alloy improved the stress rupture lives significantly for as-cast, as-heat treated and thermal exposed samples. The improvement of the stress rupture properties may be attributed to the restraint of $\mu$ phase precipitation and growth by the proper addition of $\mathrm{Ru}$.
\end{abstract}

\section{Introduction}

Single crystal nickel base superalloys are the key materials for turbine blades of aircraft engines. With the increase of thrustweight ratio and operation temperature for aircraft engines, the requirement for superalloys on their high temperature capability is getting higher and higher year by year. In order to increase the service temperature of single crystal nickel base superalloys, large amount of refractory alloying elements, such as $\mathrm{W}, \mathrm{Mo}, \mathrm{Nb}, \mathrm{Ta}$, $\mathrm{Re}$, have been used ${ }^{[1,2]}$. It has been found that the addition of rhenium plays an important role on high temperature creep resistance in single crystal nickel base superalloys ${ }^{[3,4]}$. However, $\operatorname{Re}$ has a strong segregation tendency in the $\gamma$ phase, and homogenization of $\mathrm{Re}$ is very difficult even at the temperatures above $1300^{\circ} \mathrm{C}$ for a long time, consequently the TCP phase which is harmful to mechanical properties may precipitate during long term high temperature service ${ }^{[5]}$. Moreover, Re is rare resource and very expensive element. The costs of alloys increase by about $100 \%$ with the addition of 1 wt. $\%$ Re.

The addition of $\mathrm{Ru}$ not only prohibits the precipitation of TCP phase during high temperature service of the alloys but also strengthens $\gamma$ and $\gamma^{\prime}$ phases effectively ${ }^{[6]}$. In recently developed fourth generation single crystal alloys, such as TMS-138, TMR-
139, TMS-162 and MC-NG, the content of Re decreased from $6 \%$ which is the usual content in third generation single crystal alloys to $4 \sim 5$ wt. $\%$, and added $2 \sim 4$ wt. $\%$ of $\mathrm{Ru}$ to prevent the formation of TCP phase ${ }^{[7,8]}$. The elemental electron hole numbers, $\mathrm{Nv}$, of these new single crystal alloys were controlled within the values smaller than 2 to increase the microstructure stability for high temperature service of the alloys. There have been quite few reports on the effect of $\mathrm{Ru}$ on the microstructure and stress rupture properties of single crystal superalloys ${ }^{[6-10]}$.

In this investigation two single crystal alloys with $3 \mathrm{wt} . \%$ Re with the electron hole number of 2.2 have been prepared. The effect of $\mathrm{Ru}$ on the microstructure and stress rupture properties of single crystal nickel base superalloys with high content of refractory elements of $\mathrm{W}, \mathrm{Mo}, \mathrm{Nb}$, Ta and low Re (3 wt.\%) have been systematically studied.

\section{Materials and Experimental Procedure}

Two heats of $5 \mathrm{~kg}$ master alloys ingots were prepared in a vacuum induction furnace. The chemical compositions of the alloys used in this investigation are listed in Table I. The basic compositions of the two alloys are the same, except that Alloy 1 is Ru free and Alloy 2 contains 4 wt.\% Ru. The single crystal bars with the dimension of $\varphi 15 \times 150 \mathrm{~mm}$ were produced in $<001>$ direction by screw selection method with the mould drawing rate of $4 \mathrm{~mm} / \mathrm{min}$ in a directional solidification vacuum induction furnace. Laue back-reflection technique was used to determine the longitudinal crystal orientation of each bar. The single crystal bars with the longitudinal crystal orientation within 10 degree of the $<001>$ direction were used in this study. The multiple steps heat treatments of $1315^{\circ} \mathrm{C} / 16$ h.A.C $+1140^{\circ} \mathrm{C} / 4$ h.A.C $+870^{\circ} \mathrm{C} / 20$ h.A.C and $1305^{\circ} \mathrm{C} / 16 \mathrm{~h}$.A.C $+1140^{\circ} \mathrm{C} / 4 \mathrm{~h} . \mathrm{A} . \mathrm{C}+870^{\circ} \mathrm{C} / 20 \mathrm{~h}$.A.C were given to single crystal bars of Alloy 1 and Alloy 2, respectively. In order to study the microstructure stability at high temperatures the both specimens of Alloy 1 and 2 were thermal exposed at the temperature of $1100^{\circ} \mathrm{C}$ for $500 \mathrm{~h}$. The tensile stress rupture specimens with the size of $\varphi 5 \times 65 \mathrm{~mm}$ were machined from single crystal bars under the conditions of as-cast, after heat treatments and thermal exposure. The tensile stress rupture tests were conducted under the conditions of $1100^{\circ} \mathrm{C} / 137 \mathrm{MPa}$.

The etchant used for microstructure study was

\begin{tabular}{|c|c|c|c|c|c|c|c|c|c|c|c|c|}
\hline \multicolumn{13}{|c|}{ Table I. Chemical compositions of experimental alloys } \\
\hline \multicolumn{2}{|c|}{ Alloy } & $\mathrm{Cr}$ & Co & Mo & $\mathrm{Al}$ & $\mathrm{Ti}$ & $\mathrm{W}$ & $\mathrm{Nb}$ & $\mathrm{Ta}$ & $\operatorname{Re}$ & $\mathrm{Ru}$ & $\mathrm{Ni}$ \\
\hline \multirow{2}{*}{1} & wt. $\%$ & 4.75 & 9.84 & 4.01 & 5.68 & 1.02 & 3.85 & 0.55 & 7.66 & 3.00 & & 59.64 \\
\hline & at. $\%$ & 5.59 & 10.2 & 2.56 & 12.8 & 1.30 & 1.28 & 0.36 & 2.59 & 0.99 & & 62.33 \\
\hline \multirow{2}{*}{2} & wt. $\%$ & 4.57 & 9.46 & 4.00 & 5.47 & 0.98 & 3.77 & 0.53 & 7.38 & 2.83 & 3.96 & 57.05 \\
\hline & at. $\%$ & 5.47 & 9.99 & 2.60 & 12.6 & 1.27 & 1.27 & 0.36 & 2.54 & 0.95 & 2.44 & 60.51 \\
\hline
\end{tabular}


$\mathrm{HNO}_{3}: \mathrm{HF}: \mathrm{C}_{3} \mathrm{H}_{8} \mathrm{O}_{2}=1: 3: 5$. The microstructures of as-cast, heat treated and creep ruptured samples were analyzed by optical microscope, SEM, EDS, EPMA and X-ray diffraction techniques.

\section{Results and Discussion}

Microstructures of As-cast and Heat Treated Alloys

Microstructure of as-cast alloys. The microstructures of as-cast Alloy 1 and Alloy 2 are shown in Figure 1, which are the SEM secondary electron images. It can be seen that the microstructure of the alloy consists of $\gamma$ matrix, primary $\gamma^{\prime}$ phase in the dendrites and interdendritic areas and $\gamma / \gamma^{\prime}$ eutectics in the interdendritic area The particle size of $\gamma^{\prime}$ phase in dendrites areas (A region) is finer than that in interdendritic area (B region). The petal like $\gamma / \gamma^{\prime}$ eutectics ( $\mathrm{C}$ region) appeared in interdendritic area with the size of $30 \sim 50 \mu \mathrm{m}$. The volume fraction of $\gamma / \gamma^{\prime}$ eutectics is about $28 \%$. mainly enriched in dendrite area during solidification process and $\mathrm{Al}$, Ta tended to segregated in interdendritic area, especially enriched in $\gamma / \gamma^{\prime}$ eutectics. The results in Table II showed that Ru slightly segregated in the dendrite area. Compared to Re and W, $\mathrm{Ru}$ is a weak segregation element.

Microstructure of the alloys after heat treatment and thermal exposure. The microstructures of heat treated alloys are shown in Figure 2, indicating that the primary $\gamma^{\prime}$ and $\gamma / \gamma^{\prime}$ eutectic phases dissolved completely after the high temperature solution treatment, and the cubic shaped $\gamma^{\prime}$ phase precipitated during the subsequent aging of $1140^{\circ} \mathrm{C} / 4 \mathrm{~h}$.A.C $+870^{\circ} \mathrm{C} / 20 \mathrm{~h}$.A.C. It has been found that the addition of $\mathrm{Ru}$ did not change the shape and size of $\gamma^{\prime}$ phase. However, the addition of $\mathrm{Ru}$ decreased the dissolving temperature of $\gamma / \gamma^{\prime}$ eutectic by $10^{\circ} \mathrm{C}$, i. e., $1315^{\circ} \mathrm{C} / 16 \mathrm{~h}$ for Alloy 1 and $1305^{\circ} \mathrm{C} / 16 \mathrm{~h}$ for Alloy 2. A small amount of rod shaped particles with size of about $1.5 \mu \mathrm{m}$ long and $0.5 \mu \mathrm{m}$ width, which was
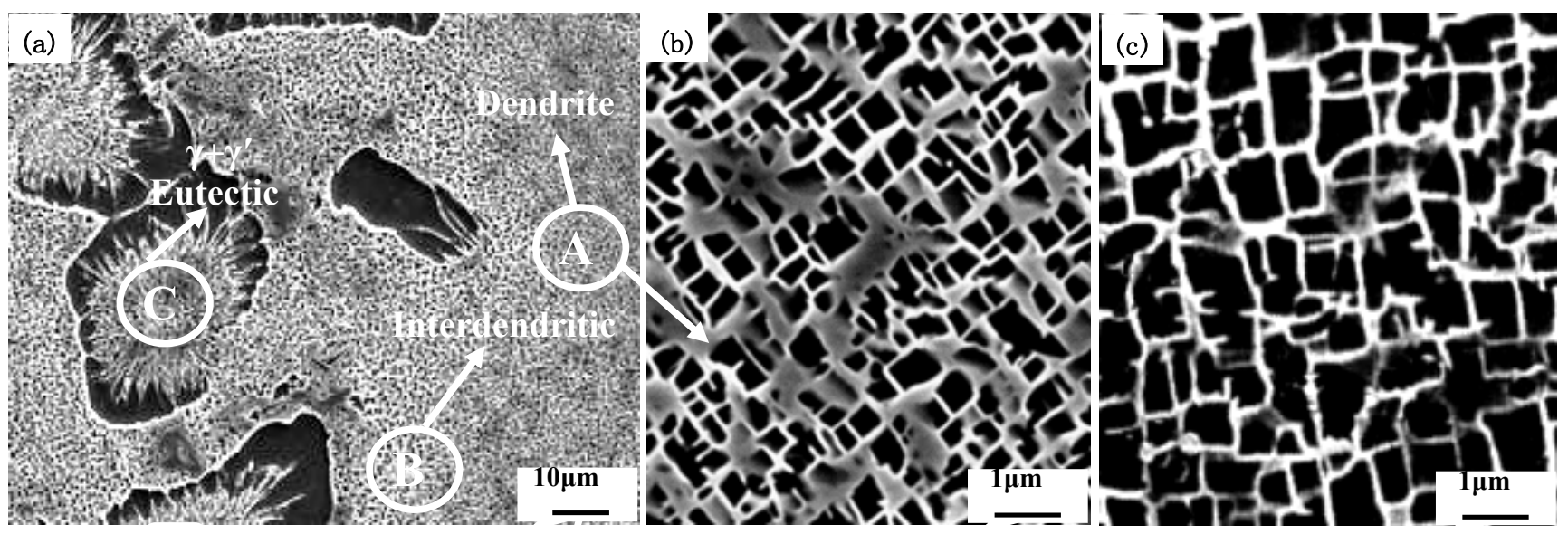

(c)

Fig.1 Secondary electron images of the as-cast Alloy 1 (a) general microstructure (b) local magnified image (Dendrite) (c) local magnified image (Interdendritic).

\begin{tabular}{|c|c|c|c|c|c|c|c|c|c|c|c|}
\hline \multicolumn{12}{|c|}{ Table II. Chemical compositions of as-cast Alloy 1 and Alloy 2 in the different region (wt.\%) } \\
\hline Alloy & Region & $\mathrm{Al}$ & $\mathrm{Ti}$ & Mo & W & $\operatorname{Re}$ & $\mathrm{Ta}$ & $\mathrm{Cr}$ & Co & $\mathrm{Ru}$ & $\mathrm{Ni}$ \\
\hline \multirow{3}{*}{1} & Dentrite & 4.41 & 0.74 & 3.82 & 5.56 & 4.48 & 5.66 & 4.75 & 11.0 & & 59.58 \\
\hline & Interdentrite & 5.79 & 1.09 & 4.11 & 3.59 & 2.07 & 8.03 & 5.46 & 9.68 & & 60.18 \\
\hline & eutectic $\gamma^{\prime}$ & 7.63 & 1.59 & 2.12 & 1.20 & 0.43 & 11.7 & 2.09 & 7.34 & & 65.90 \\
\hline \multirow{3}{*}{2} & Dentrite & 4.57 & 0.71 & 3.76 & 5.18 & 4.31 & 5.73 & 4.58 & 11.0 & 4.03 & 56.13 \\
\hline & Interdentrite & 5.72 & 0.99 & 4.21 & 3.42 & 2.34 & 8.12 & 5.35 & 9.43 & 3.85 & 56.57 \\
\hline & eutectic $\gamma^{\prime}$ & 7.33 & 1.36 & 2.24 & 1.32 & 0.49 & 11.7 & 1.98 & 7.67 & 2.89 & 63.02 \\
\hline
\end{tabular}

In the high magnification photos of Figure $1 \mathrm{~b}$ and Figure 1c, it can be seen that the cubic shaped $\gamma^{\prime}$ particles precipitated in the $\gamma$ matrix. The average sizes of $\gamma^{\prime}$ particles are $0.3 \sim 0.5 \mu \mathrm{m}$ in dendrites and $0.9 \sim 1.1 \mu \mathrm{m}$ in the interdendritic area, and the shape of the $\gamma^{\prime}$ particles in the dendrite is more cubic than that in the interdendritic area.

Table II shows the chemical compositions of different areas measured by EPMA. It can be seen that the element segregation existed during the solidification process of both alloys, especially for the elements of Re, W, Al and Ta. Among them Re and W determined to be the $\mu$ phase, precipitated in the $\gamma$ matrix of Alloy 1 after the aging treatment. There was no TCP phase formed in Alloy 2 during the same heat treatment, indicating that the addition of 4 wt.\% Ru can inhibit the formation of TCP phase.

Figure 3(a)-(f) shows the microstructures of the two alloys after the thermal exposures under the conditions of $1100^{\circ} \mathrm{C} / 20 \mathrm{~h}$, $1100^{\circ} \mathrm{C} / 100 \mathrm{~h}$ and $1100^{\circ} \mathrm{C} / 1000 \mathrm{~h}$, respectively. With the thermal exposure at $1100^{\circ} \mathrm{C}$ for $20 \mathrm{~h}$, the morphology of $\gamma^{\prime}$ phase particles in Alloy 1 and Alloy 2 was still in the cubic shape without evident coarsening. And it has been observed that a small amount of rod like new phases precipitated in Alloy1. 

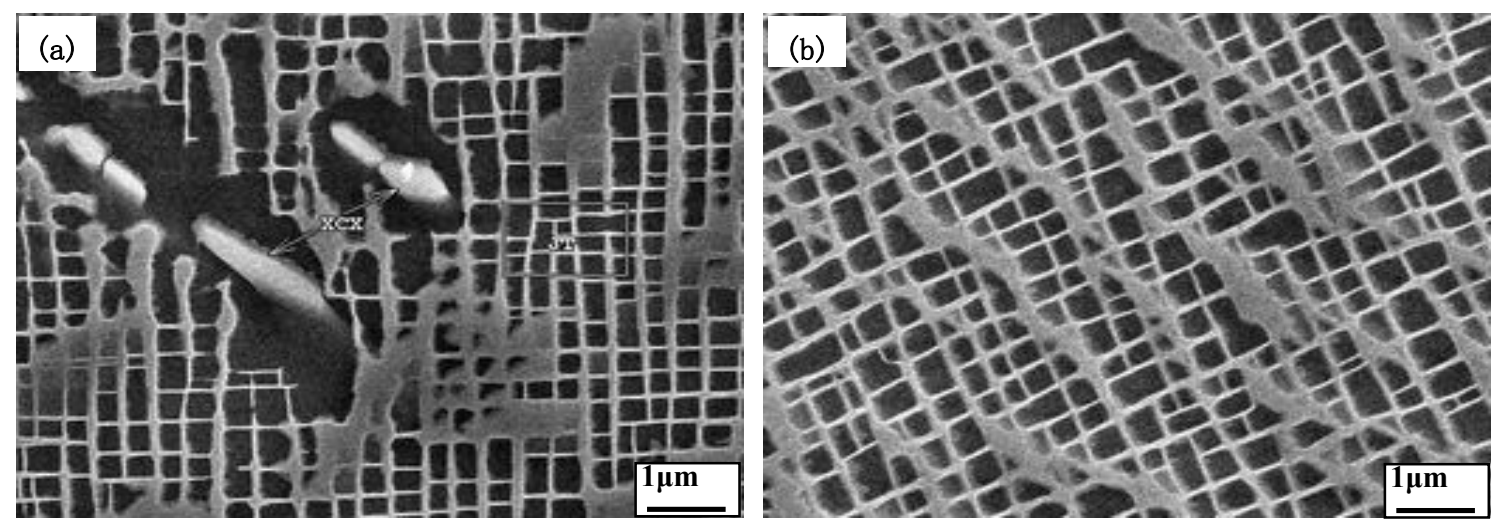

Fig. 2 Microstructure of Alloy 1 and Alloy 2 after heat treatments of (a) Alloy 1: $1315^{\circ} \mathrm{C} / 16 \mathrm{~h} \mathrm{A.C}+1140^{\circ} \mathrm{C} / 4 \mathrm{~h}$
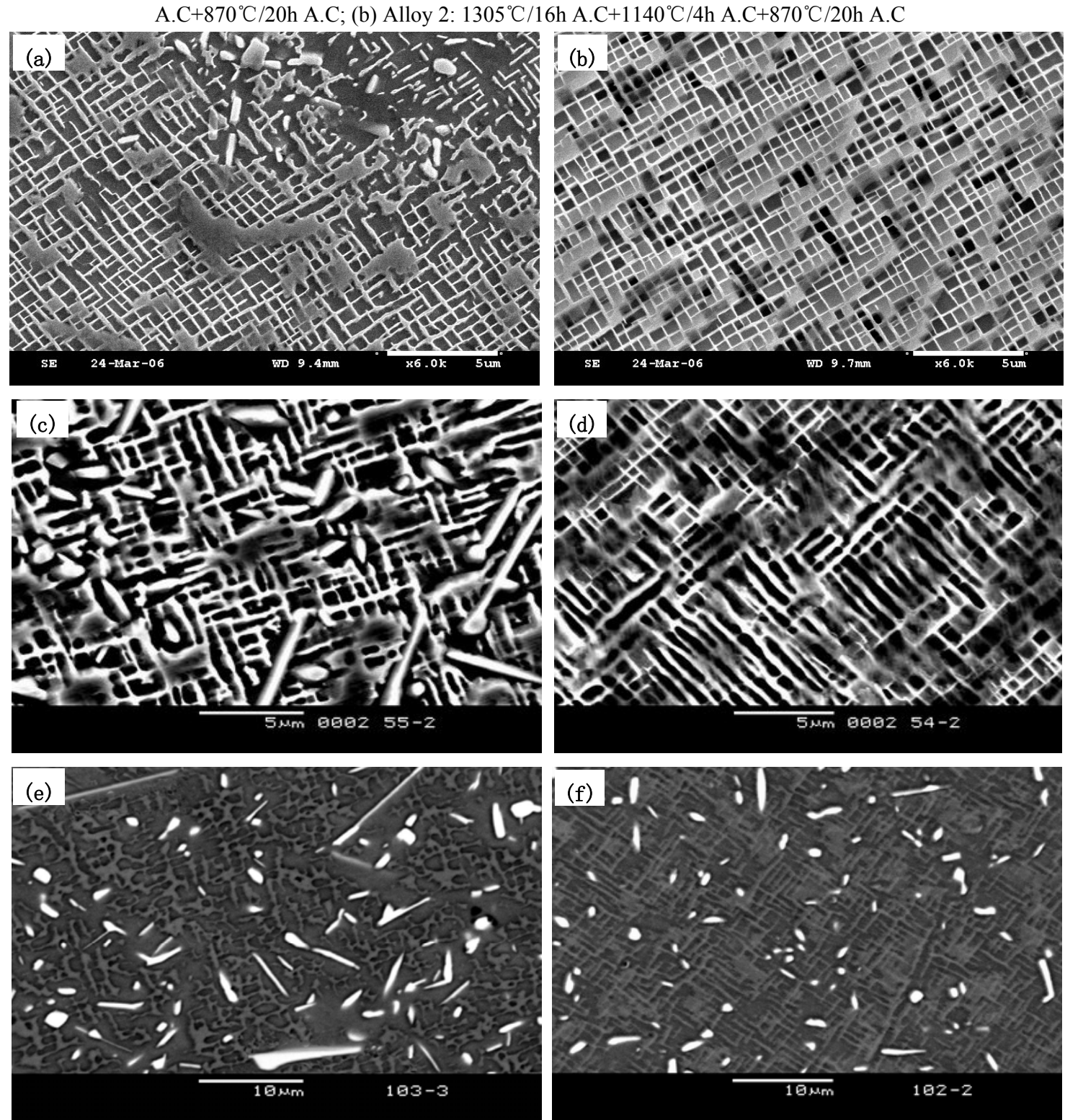

Fig. 3 Microstructures of the two alloys after thermal exposure at $1100^{\circ} \mathrm{C}$ for (a) Alloy 1, 20h; (b) Alloy 2, 20h; (c) Alloy 1, 100h; (d) Alloy 2, 100h; (e) Alloy 1, 1000h; (f) Alloy 2, 1000h. 
After exposure at $1100^{\circ} \mathrm{C}$ for $100 \mathrm{~h}$ large amount of rod like $\mu$ phase formed in Alloy 1, and the $\gamma^{\prime}$ phase particles grew up and joined with each other to form raft structure locally. While for Alloy 2, after exposure of $1100^{\circ} \mathrm{C} / 100 \mathrm{~h}$, the raft structure formed significantly, indicating that the addition of $\mathrm{Ru}$ can promote the formation of the raft structure through the coarsening of $\gamma^{\prime}$ phase particles. However there was no rod like TCP phase formed in Alloy 2 after the thermal exposure of $1100{ }^{\circ} \mathrm{C} / 100 \mathrm{~h}$, which indicates that the addition of Ru can inhibit the formation of TCP phase. In the exposure condition of $1100^{\circ} \mathrm{C} / 1000 \mathrm{~h}$, a large amount of $\mu$ phase precipitated in both alloys, and the amount of $\mu$ phase was more in Alloy 1 than in Alloy 2. Moreover, the size of large TCP particles with needle shape in Alloy 1 reached $25 \sim 30 \mu \mathrm{m}$. Whereas in Alloy 2 the average size of the most TCP phase was about $1.5 \mu \mathrm{m}$, indicating that the addition of $\mathrm{Ru}$ can not only inhibit the precipitation of the $\mu$ phase but also strongly restrain the growth of the $\mu$ phase.

Morphologies and composition analysis of TCP phase. The TCP phase in Alloy 1 and Alloy 2 after $1100^{\circ} \mathrm{C} / 1000 \mathrm{~h}$ exposure were electrochemically extracted using a special echant. The X-ray diffraction patterns and the morphology of the extracted TCP phase are shown in Figure 4 and 5, respectively. The analysis of $\mathrm{X}$-ray diffraction patterns in Figure 4 indicated that the extracted phase is the trigonal structured $\mu$ phase with the lattice parameters of $\mathrm{a}=0.4740 \mathrm{~nm}, \mathrm{c}=2.5738 \mathrm{~nm}$ for Alloy 1 and $\mathrm{a}=0.4760 \mathrm{~nm}$, $\mathrm{c}=2.5833 \mathrm{~nm}$ for Alloy 2. The previous investigation ${ }^{[11]}$ showed that the crystal orientation relationships between the $\mu$ phase and $\gamma / \gamma^{\prime}$ phase were $(111)_{\mu} \|(111)_{\gamma / \gamma^{\prime}}$ and $[01 \overline{1}]_{\mu} \|[11 \overline{2}]_{\gamma / \gamma^{\prime}}$.

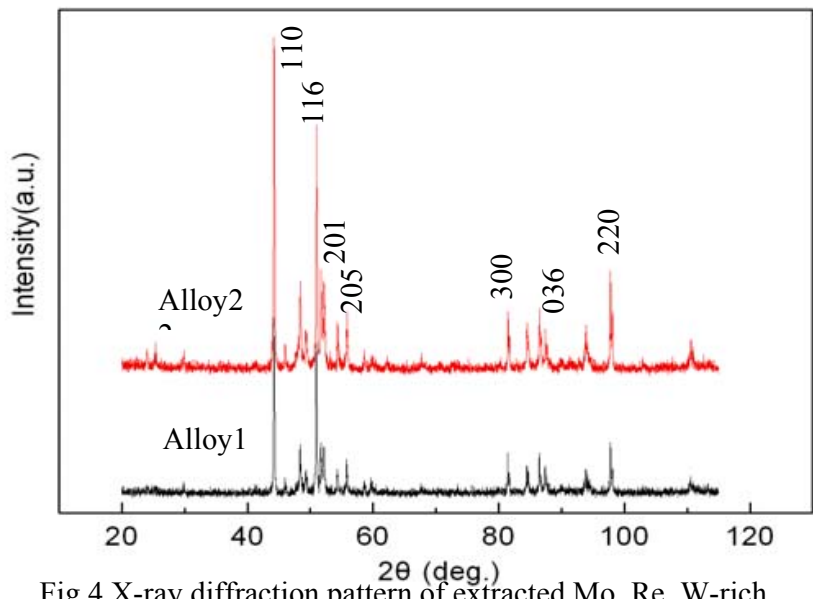

Fig. 4 X-ray diffraction pattern of extracted Mo, Re, W-rich precipitates taken from the Alloy 1 and Alloy 2 thermally exposed at $1100^{\circ} \mathrm{C}$ for $1000 \mathrm{~h}$, indicating these precipitates are $\mu$ phase.
The chemical compositions of the $\mu$ phase electrochemically extracted from Alloy 1 and Alloy 2 after $1100^{\circ} \mathrm{C} / 500 \mathrm{~h}$ thermal exposure are listed in Table III, which were measured by EPMA. It can be found that the $\mu$ phase mainly consists of $\mathrm{Ni}, \mathrm{Mo}, \mathrm{W}, \mathrm{Re}$, $\mathrm{Co}, \mathrm{Cr}, \mathrm{Nb}$ and $\mathrm{Ta}$. Compared with the results in Table I, it shows that the contents of the elements $\mathrm{Mo}, \mathrm{W}, \mathrm{Re}, \mathrm{Co}, \mathrm{Cr}$ and $\mathrm{Nb}$ in the $\mu$ phase are higher than in the alloys. It can be seen that the $\mu$ phase is especially rich in Mo, $\mathrm{W}$ and $\mathrm{Re}$, while not rich in $\mathrm{Ru}, \mathrm{i}$. e., the content of $\mathrm{Ru}$ in the $\mu$ phase is $1.96 \mathrm{wt} . \%$, which is much lower than the average composition of the alloy. This indicates that $\mathrm{Ru}$ is not the main forming element of the $\mu$ phase.

Influence of $\mathrm{Ru}$ addition on high temperature stress rupture properties

The tensile stress rupture lives under the test conditions of $1100^{\circ} \mathrm{C} / 137 \mathrm{MPa}$ of as-cast, heat treated, thermal exposed alloys are listed in Table IV. It can be observed that the average stress rupture lives of Alloy 2 are longer than that of Alloy 1 by $34 \%$, $46 \%$ and $48 \%$ for as-cast, as-heat treated and thermal exposed samples, respectively, indicating that the addition of $\mathrm{Ru}$ can improve the high temperature stress rupture properties of the alloys.

Figure 6 shows the cross section microstructures parallel to the stress axis of the ruptured specimens at $10 \mathrm{~mm}$ away from the fracture surface under the specimens conditions of as-cast, full heat treatment and thermal exposure.

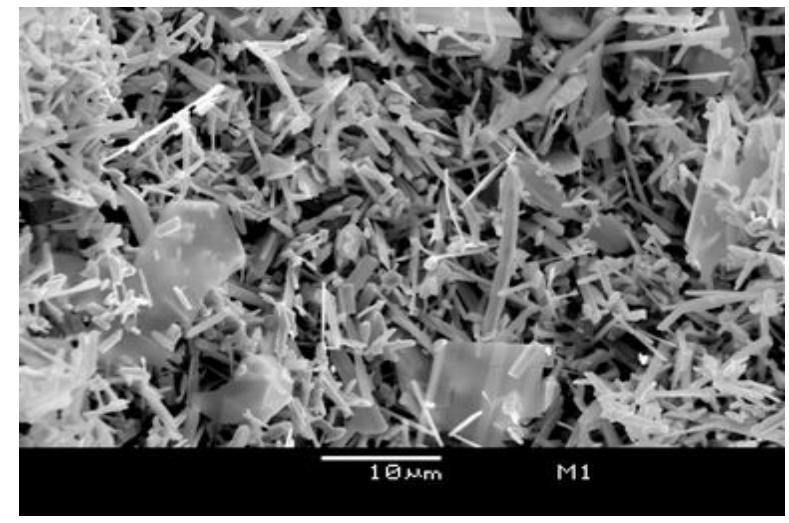

Fig.5 SEM micrograph of $\mu$ phase precipitates electrochemically extracted from alloy 1 thermally exposed at $1100^{\circ} \mathrm{C}$ for $1000 \mathrm{~h}$.

\begin{tabular}{|c|c|c|c|c|c|c|c|c|c|c|c|c|}
\hline \multicolumn{10}{|c|}{ Table III. Compositions of the $\mu$ phase in Alloy 1 and Alloy 2 thermally exposed at $1100^{\circ} \mathrm{C}$ for $500 \mathrm{~h}$} \\
\hline \multicolumn{1}{|c|}{ Alloy } & $\mathrm{Al}$ & $\mathrm{Ti}$ & $\mathrm{Mo}$ & $\mathrm{W}$ & $\mathrm{Re}$ & $\mathrm{Ta}$ & $\mathrm{Cr}$ & $\mathrm{Co}$ & $\mathrm{Nb}$ & $\mathrm{Ru}$ & $\mathrm{Ni}$ \\
\hline 1 & wt.\% & 0.97 & 0.26 & 20.24 & 11.73 & 9.73 & 4.90 & 13.02 & 12.80 & 0.78 & & 25.57 \\
\hline 1 & at.\% & 2.75 & 0.42 & 16.14 & 4.88 & 4.00 & 2.07 & 19.16 & 16.62 & 0.64 & & 33.32 \\
\hline 2 & wt.\% & 0.86 & 0.20 & 19.8 & 11.8 & 9.54 & 4.55 & 13.2 & 12.5 & 0.75 & 1.96 & 24.84 \\
\hline 2 & at.\% & 2.45 & 0.32 & 15.87 & 4.94 & 3.94 & 1.93 & 19.57 & 16.31 & 0.62 & 1.49 & 32.56 \\
\hline
\end{tabular}



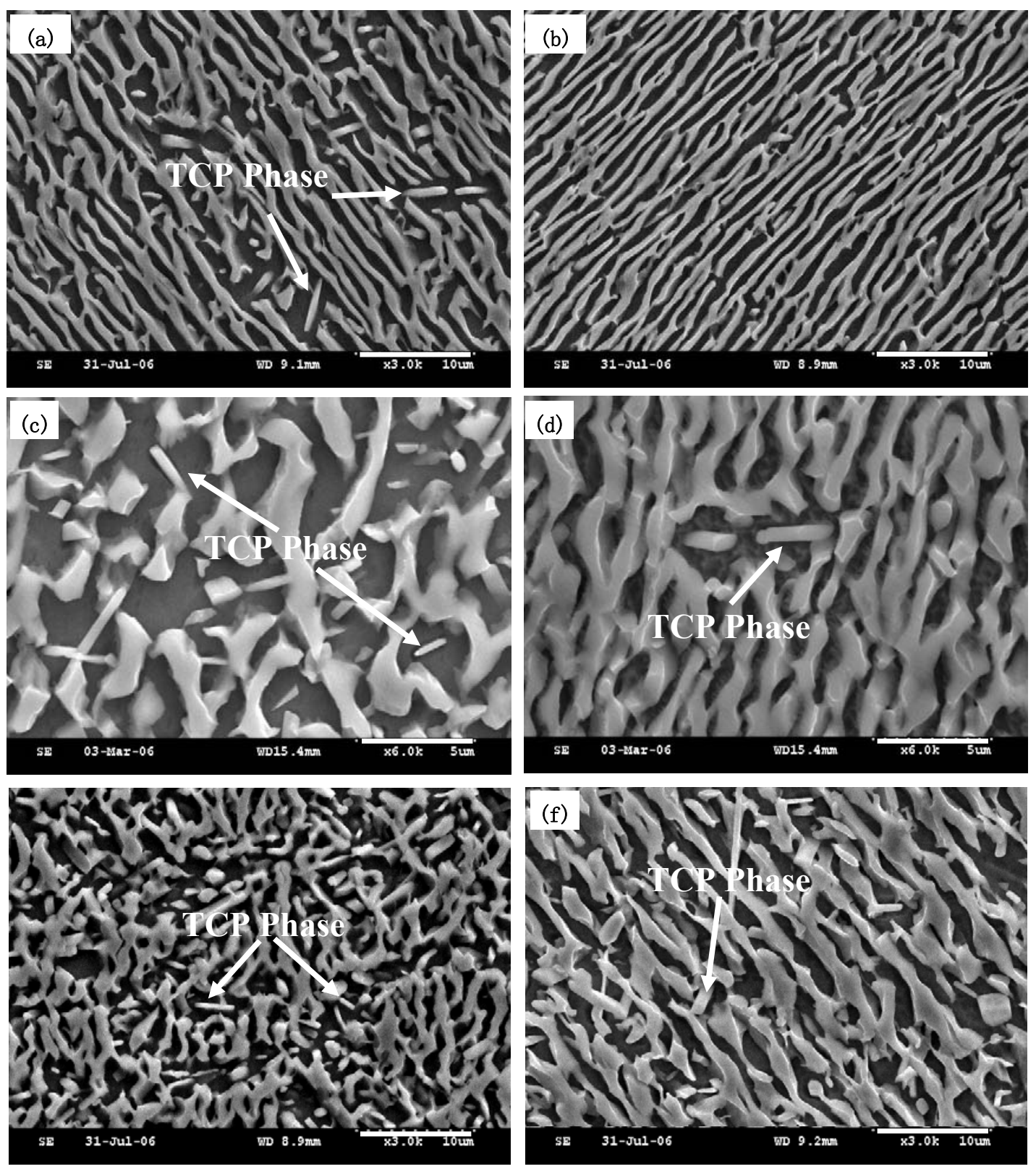

Fig. 6 Microstructures on longitudinal section at $10 \mathrm{~mm}$ away from the fracture surface of the alloys under the stress rupture testing conditions of $1100^{\circ} \mathrm{C} / 137 \mathrm{MPa}$

(a) as-cast Alloy 1; (b) as-cast Alloy 2; (c) Alloy 1: full heat treatment; (d) Alloy 2: full heat treatment; (e)Alloy 1: full heat treatment and $1100^{\circ} \mathrm{C} / 300 \mathrm{~h}$ thermal exposure (f) Alloy 2: full heat treatment and $1100^{\circ} \mathrm{C} / 300 \mathrm{~h}$ thermal exposure

\begin{tabular}{|c|c|c|}
\hline \multicolumn{3}{|c|}{ Table IV. Stress rupture lives of two alloys under $1100^{\circ} \mathrm{C} / 137 \mathrm{MPa}$} \\
\hline Alloy & Specimens Condition & Lives (h) \\
\hline 1 & as-cast & $22.19 ; 24.72$ \\
\hline 2 & as-cast & $32.34 ; 30.58$ \\
\hline 1 & $1315^{\circ} \mathrm{C} / 16 \mathrm{~h}$ A.C $+1140^{\circ} \mathrm{C} / 4 \mathrm{~h}$ A.C $+870^{\circ} \mathrm{C} / 20 \mathrm{~h}$ A.C & $91.17 ; 99.28$ \\
\hline 2 & $1305^{\circ} \mathrm{C} / 16 \mathrm{~h} \mathrm{A.C}+1140^{\circ} \mathrm{C} / 4 \mathrm{~h} \mathrm{A.C}+870^{\circ} \mathrm{C} / 20 \mathrm{~h}$ A.C & $149.77 ; 128.46$ \\
\hline 1 & $1315^{\circ} \mathrm{C} / 16 \mathrm{~h} \mathrm{~A} \cdot \mathrm{C}+1140^{\circ} \mathrm{C} / 4 \mathrm{~h} \mathrm{~A} \cdot \mathrm{C}+870^{\circ} \mathrm{C} / 20 \mathrm{~h} \mathrm{A.C}+1100^{\circ} \mathrm{C} / 300 \mathrm{~h} \mathrm{A.C}$ & $64.78 ; 68.59$ \\
\hline 2 & $1305^{\circ} \mathrm{C} / 16 \mathrm{~h} \mathrm{~A} \cdot \mathrm{C}+1140^{\circ} \mathrm{C} / 4 \mathrm{~h} \mathrm{~A} \cdot \mathrm{C}+870^{\circ} \mathrm{C} / 20 \mathrm{~h} \mathrm{~A} \cdot \mathrm{C}+1100^{\circ} \mathrm{C} / 300 \mathrm{~h}$ A.C & $101.24 ; 95.49$ \\
\hline
\end{tabular}


By comparing the microstructures of the specimens before and after rupture, it can be seen that the $\gamma^{\prime}$ phase coarsened to form the raft structure for all the specimens. It has been found that high amount of $\mu$ phase precipitated and grew up in Alloy 1 in any conditions, which destroyed the completeness of raft structure. However $\mu$ phase was not found in as-cast Alloy 2 and only small amount of $\mu$ phase formed in Alloy 2 after heat treatment and high temperature exposure, and the completeness of the raft structure in Alloy 2 is higher than that in Alloy 1.

From the experimental results mentioned above it can be seen that the addition of proper amount of Ru addition improved the stress rupture properties of the present single crystal alloy significantly. The reasons for the improvement may be as follows.

(1) More effective solution strengthening of $\gamma$ phase by higher contents of $\mathrm{W}, \mathrm{Mo}$ and $\mathrm{Re}$ in $\mathrm{Ru}$ containing alloy. In the Ru-free alloy, the reaction of $\gamma \rightarrow \gamma^{\prime}+\mu$ occurred during the heat treatment and stress rupture tests, and the precipitation and growth of $\mu$ phase with high content of W, Mo, Re lead to the decrease of the effective solution strengthening elements contents in the rest of $\gamma$ phase, which weakens the solution strengthening effect in the $\gamma$ phase. The addition of $\mathrm{Ru}$ can suppress the precipitation and growth of the $\mu$ phase, and hence improve the strength of $\gamma$ phase, which is significant to improve the high temperature stress rupture properties.

(2) The addition of proper amount of Ru leads to the formation of the relatively complete and regular raft structure. In the Ru-free alloy, the higher amount of $\mu$ phase precipitated during both heat treatment and high temperature stress rupture tests, and this destroyed the completeness of the raft structure. It is considered that the complete and regular raft structure acts as the effective barriers for dislocation climbing at high temperature. Therefore, the addition of proper amount of $\mathrm{Ru}$ in Alloy 2 made the raft structure more complete and regular, and hence improved the high temperature stress rupture properties effectively.

(3) The addition of $\mathrm{Ru}$ not only suppressed and delayed the precipitation of the $\mu$ phase but also changed the shape of the $\mu$ phase, i. e., from the needle, rod and plate shapes in Ru free alloy to mainly the rod shape in $\mathrm{Ru}$ containing alloy, and the size of the phase was decreased as well. Since $\mu$ phase is a brittle TCP phase which is harmful to the creep resistance, the improvement of the amount, size and shape of the $\mu$ phase will be benefit to the high temperature stress rupture properties.
Analysis for the effect of Ru on the microstructure stability of the $\underline{\text { alloys }}$

After the $\mu$ phase was extracted from the alloys after thermal exposed at $1100{ }^{\circ} \mathrm{C}$ for $1000 \mathrm{~h}$, the $\gamma^{\prime}$ phase was extracted from $\gamma$ matrix using electrolytic extraction method with a special solution. The chemical compositions of $\gamma$ and $\gamma^{\prime}$ phases were analyzed by inductively-coupled plasma spectrometer (ICP), using distribution coefficient to characterize the distribution behavior of the alloying elements among $\gamma$ and $\gamma^{\prime}$ phases. The coefficients $\left(\mathrm{k}_{\mathrm{i}}\right.$ or $\left.\mathrm{k}_{\mathrm{i}}{ }^{\prime}\right)$ were calculated from the equation of $\mathrm{k}_{\mathrm{i}}{ }^{\prime}=X_{i y^{\prime}} / X_{i y}$ and $\mathrm{k}_{\mathrm{i}}=X_{i y} / X_{i y^{\prime \prime}}$, where $\mathrm{k}_{\mathrm{i}}>1$ indicating alloying elements which segregate in $\gamma$ phase, $\mathrm{k}_{\mathrm{i}}{ }^{\prime}>1$ indicating alloying elements which segregate in $\gamma^{\prime}$ phase. The results were listed in Table $\mathrm{V}$.

The comparison of the distribution coefficients of alloying elements are shown in Figure 7. It can be seen that the distribution behaviors of the same element in $\gamma$ and $\gamma^{\prime}$ phases were similar in both Alloy 1 and Alloy 2. The results of ( $\mathrm{k}_{\mathrm{Re}}, \mathrm{k}_{\mathrm{W}}, \mathrm{k}_{\mathrm{Mo}}, \mathrm{k}_{\mathrm{Cr}}, \mathrm{k}_{\mathrm{Co}}$, $\mathrm{k}_{\mathrm{Ru}}>1$ ) indicate that the elements $\mathrm{Re}, \mathrm{W}, \mathrm{Mo}, \mathrm{Cr}, \mathrm{Co}, \mathrm{Ru}$ tend to enrich in the $\gamma$ phase. Among these elements, Re has the strong segregation tendency in $\gamma$ phase. Elements $\mathrm{Cr}$, Mo, Co, W have smaller segregation tendency and Ru has the smallest segregation tendency in $\gamma$ phase.

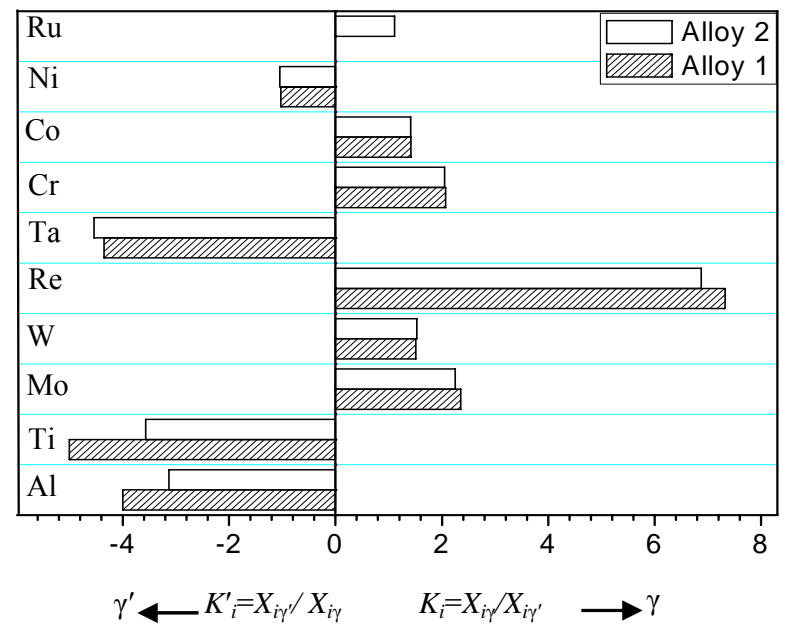

Fig 7. The comparison of the distribution coefficients of alloying elements

\begin{tabular}{|c|c|c|c|c|c|c|c|c|c|c|c|}
\hline Alloy & Position & $\Delta 1$ & $T:$ & & & & & & & $\mathrm{D}_{3}$ & \\
\hline \multirow{4}{*}{1} & & & & & & & & & & & \\
\hline & $\gamma$ & 1.89 & 0.32 & & 5.17 & 5.58 & 2.50 & 0.23 & 13.25 & & 59.30 \\
\hline & $\gamma^{\prime}$ & 8.76 & 1.83 & 2.31 & 3.26 & 0.60 & 12.26 & 2.23 & 7.03 & & 61.72 \\
\hline & Partitioning coefficient & 0.21 & 0.17 & 2.55 & 1.58 & 9.30 & 0.19 & 2.79 & 1.88 & & 0.96 \\
\hline \multirow{3}{*}{2} & $\gamma$ & 2.37 & 0.45 & 5.83 & 5.24 & 5.44 & 2.42 & 6.35 & 13.34 & 4.11 & 54.45 \\
\hline & $\gamma^{\prime}$ & 7.98 & 1.71 & 2.37 & 3.38 & 0.64 & 12.49 & 2.24 & 7.10 & 3.59 & 58.5 \\
\hline & Partitioning coefficient & 0.29 & 0.26 & 2.46 & 1.55 & 8.50 & 0.19 & 2.83 & 1.87 & 1.14 & 0.93 \\
\hline
\end{tabular}


Results of $\mathrm{k}_{\mathrm{Ti}}^{\prime} 、 \mathrm{k}_{\mathrm{Ta}}^{\prime} 、 \mathrm{k}_{\mathrm{Al}}^{\prime} 、 \mathrm{k}_{\mathrm{Ni}}^{\prime}>1$ indicate that the elements $\mathrm{Ti}$, $\mathrm{Ta}, \mathrm{Al}, \mathrm{Ni}$ tend to segregate in $\gamma^{\prime}$ phase, and the elements Ti, Ta, Al showed stronger segregation tendency than $\mathrm{Ni}$. The addition of $\mathrm{Ru}$ didn't change the distribution character of the elements but change the distribution coefficients of these elements, decreased the segregation tendency of $\mathrm{Al}, \mathrm{Ti}, \mathrm{Mo}$ and Re. From above analysis, it may be concluded that the addition of $\mathrm{Ru}$ can make the $\gamma^{\prime}$ phase formation elements $\mathrm{Al}$, Ti to enter in $\gamma$ phase, and make the $\gamma$ phase formation elements of Re, W, Mo enter in $\gamma^{\prime}$ phase. Therefore the saturation degrees of the elements (Re, W, Mo) were lowered by $\mathrm{Ru}$ addition, which can inhibit the precipitation of TCP phase, and hence stabilize the microstructure of the alloys.

\section{Conclusions}

1. The addition of 4 wt.\% Ru suppressed the precipitation and growth of the TCP phase during the long term thermal exposure at $1100^{\circ} \mathrm{C}$, and increased the microstructure stability of the present single crystal Ni base superalloy.

2. $\mathrm{Ru}$ is a weak segregation element, and mainly distributes in $\gamma$ phase, and has strong effect to form the raft structure during thermal exposure and creep tests.

3. The addition of Ru has effect on the partitioning coefficients of some alloying elements, i. e., decreased the segregation degrees of $\mathrm{Al}, \mathrm{Ti}, \mathrm{Mo}$ and $\mathrm{Re}$ in $\gamma$ and $\gamma^{\prime}$ phases, hence suppressing the precipitation of TCP phase and stabilizing the microstructure of the alloy.

4. Under the testing condition of $1100^{\circ} \mathrm{C} / 137 \mathrm{MPa}$, the stress rupture lives of $\mathrm{Ru}$ containing alloy in the as-cast, full heat treatment and thermal exposure conditions are superior to that of $\mathrm{Ru}$ free alloy. This may attributed to the suppress of precipitation and growth of $\mu$ phase, formation of the regular and complete raft structure and the stronger solution hardening in $\gamma$ phase due to the proper addition of $\mathrm{Ru}$.

\section{Acknowledgements}

The authors would like to express their thanks to National Natural Science Foundation of China for financial support.

\section{References}

[1] G. E. Fuchs, "Solution heat treatment response of a third generation single crystal Ni-base superalloy", Materials Science and Engineering A300(2001) 52-60.

[2] S. Walston, A. Cetel, R. MacKay, "Joint development of a fourth generation single crystal superalloys", Superalloys 2004, ed. K. A. Green, et al, (Warrendale, PA:TMS, 2004), 15-24.

[3] G. L. Erickson, "The development and application of CMSX10", Superalloys 1996, ed. P. D. Kissinger, et al, (Warrendale, PA:TMS, 1996), 35-44.

[4] Y. Murata, R. Hashizume, A Yoshinari, "Alloying effects on surface stability and creep strength of nickel based single crystal superalloys containing 12 mass\%Cr", Superalloys 2000, ed.T.M. Pollock, et al, (Warrendale, PA:TMS, 2000), 285-294.

[5] C.M.F. Rae, M.S.A. Karunaratne, C.J. Small, R.W. Broomfield, C.N. Jones, and R. Reed, "Topologically Close Packed Phases in an Experimental Rhenium-Containing Single Crystal Superalloy,"
Superalloys 2000, ed. T.M. Pollock et al., (Warrendale, Pa: TMS, 2000), 767-776.

[6] K .Yutaka, K .Toshiharu, Y.Tadaharu, "Development of next generation Ni-base single crystal superalloys", Superalloys 2004, ed. K. A. Green, et al, (Warrendale, PA:TMS, 2004), 35-43.

[7] H. Zhoua, Y. Roa, H. Harada, "Deformation microstructures after low-cycle fatigue in a fourth-generation Ni-base SC superalloy TMS-138”, Mater Sci Eng, A 381 (2004) 20-27

[8] D. Argence, C. Vernault, Y. Desvallees, and D. Fournier, "MC-NG:A $4^{\text {th }}$ generation single-crystal superalloy for future aero-nautical turbine blades and vanes", Superalloys 2000, ed.T.M. Pollock, et al, (Warrendale, PA:TMS, 2000), 829-837.

[9] A.C. Yeh, S. Tin, "Effects of Ru and Re additions on the high temperature flow stresses of Ni-base single crystal superalloys", Scripta Materialia 52 (2005) 519-524.

[10] J.X. Zhang, T. Murakumo, H. Harada, "Dependence of creep strength on the interfacial dislocations in a fourth generation SC superalloy TMS-138", Scripta Materialia 48 (2003) 287-293.

[11] M. Simonetti, P. Caron, "Role and behaviour of $\mu$ phase during deformation of a nickel-based single crystal superalloy", Mater Sci Eng A, 19982 (54) 1-12. 